\title{
Influence of Annealing Technology on Drawing Properties of Cold Sheets Rolled with Compact Strip Production Hot Bands
}

\author{
Guang XU, Yi YANG, Xinqiang ZHANG and Huangqiang ZHANG
}

Key Laboratory for Ferrous Metallurgy and Resources Utilization of Ministry of Education, Wuhan University of Science and Technology, Wuhan, 430081, China. E-mail: xuguang@wust.edu.cn, random88@163.com

(Received on August 13, 2007; accepted on September 28, 2007)

\begin{abstract}
The drawing properties of cold sheets rolled with CSP hot-bands (CSS) are not so good compared to cold sheets rolled with conventional hot bands (CSC). Therefore, influences of annealing technology on drawing properties of CSS have been studied in the paper. Research works included (1) drawing properties of cold sheets rolled with different CSP hot-bands, (2) drawing properties of CSS and CSS, and (3) influences of annealing technology on drawing properties of CSS. The results of annealing experiments, microstructural examinations and drawing property tests have shown that the drawing properties of CSS at higher finish deformation temperature (FDT) and lower coiling temperature (CT) are superior to those of CSS at lower FDT and higher CT. It was also found that the drawing properties of CSC are superior to those of CSS after heat treatment with same annealing technology. The annealing temperature for experimental steel grade (DC03) should be higher than $680^{\circ} \mathrm{C}$.
\end{abstract}

KEY WORDS: CSP hot bands; cold sheets; annealing technology; drawing properties.

\section{Introduction}

The drawing properties of cold sheets produced by conventional hot bands have been systemically investigated, ${ }^{1-8)}$ and formable sheets with good drawing properties can be produced by conventional hot strips. With the application of continuous casting and rolling technology, such as compact strip production (CSP), in hot strip production, some CSP hot-bands have been used to produce formable cold sheets. But in the production, it has been found that the drawing propertied of cold sheets rolled with CSP hot-bands (CSS) are not as good as those of cold sheets rolled with conventional hot strips (CSC). In addition, few research works on formable properties of CSS have been conducted. Therefore, it is necessary to research how to produce the CSS with good drawing properties to meet the requirements of consumers for forming properties.

Influences of annealing technology on drawing properties of CSS have been investigated in the paper according to above mentioned problems in CSS production in order to provide the theoretical basis for determining annealing technology. Another purpose of research work is to provide the reference for determining finish deformation temperature (FDT) and coiling temperature (CT) in the production of CSP hot strips used for cold sheets rolling.

\section{Experimental Purposes}

The purposes of research work are as follows:

(1) Influences of different annealing technologies on microstructure and forming properties of CSS;

(2) Influences of different CSP hot bands on microstructure and forming properties of cold rolled and annealed sheets;

(3) Differences of microstructures and drawing properties of cold rolled and annealed sheets produced with CSP hot bands and conventional hot strips.

\section{Specimens and Annealing Technology}

\subsection{Specimens}

The steels used for this study are as-cold-rolled drawable sheets, which were respectively taken from cold plant, Lianyuan Steels and No. 1 Cold Mill, WISCO. Steel grade is DC03 and chemical composition of experimental steels is listed in Table 1, with Table 2 giving the FDT, CT, cold rolling reduction (CRR) etc. Cold strips in Lianyuan Steels were rolled with CSP hot-bands, whereas cold sheets in WISCO were rolled with conventional hot strips. Rectangular samples of dimensions $270 \times 60 \mathrm{~mm}$ were cut from the sheets for use in tests.

Sample X1 and X2 represent the as-cold-rolled sheets

Table 1. Chemical composition of steels in the tests (wt $\%)$.

\begin{tabular}{lccccccccc}
\hline \multicolumn{1}{c}{ Composition } & $\mathrm{C}$ & $\mathrm{Mn}$ & $\mathrm{Si}$ & $\mathrm{P}$ & $\mathrm{S}$ & $\mathrm{Ni}$ & $\mathrm{Cu}$ & $\mathrm{Al}$ & $\mathrm{N}$ \\
\hline samples from Lianyuan Steels & 0.034 & 0.212 & 0.011 & 0.031 & 0.032 & 0.010 & 0.040 & 0.041 & 0.0062 \\
samples form WISCO & 0.033 & 0.216 & 0.008 & 0.013 & 0.012 & 0.015 & 0.043 & 0.042 & 0.0032 \\
\hline
\end{tabular}


Table 2. Other parameters of test samples.

\begin{tabular}{ccccc}
\hline Sample & Number & FDT, ${ }^{\circ} \mathrm{C}$ & $\mathrm{CD},{ }^{\circ} \mathrm{C}$ & $\mathrm{CRR}, \%$ \\
\hline samples from Lianyuan Steels & $\mathrm{X} 1$ & 927 & 568 & 75 \\
samples from Lianyuan Steels & $\mathrm{X} 2$ & 890 & 646 & 73 \\
samples form WISCO & $\mathrm{X} 3$ & 905 & 650 & 75 \\
\hline
\end{tabular}

Table 3. Examination results of mechanical property and drawing property.

\begin{tabular}{ccccccc}
\hline Steel grade & Sample & $\mathrm{Rp}_{0.2}, \mathrm{MPa}$ & $\mathrm{R}_{\mathrm{el}}, \mathrm{MPa}$ & $\mathrm{R}_{\mathrm{m}}, \mathrm{MPa}$ & $\mathrm{A}_{80}$ & $\mathrm{n}$ \\
\hline & 11 & 214.3 & 188.9 & 271.8 & 30.52 & 0.24 \\
& 12 & 227.8 & 218.8 & 299.7 & 28.84 & 0.22 \\
& 13 & 256.6 & 240.5 & 297.7 & 36.63 & 0.26 \\
& 21 & 235.0 & 224.8 & 302.0 & 28.15 & 0.22 \\
DC03 & 22 & 245.1 & 228.9 & 304.2 & 26.79 & 0.20 \\
& 23 & 246.8 & 234.8 & 301.4 & 39.72 & 0.25 \\
& 31 & 212.8 & 195.6 & 283.5 & 30.78 & 0.23 \\
& 32 & 239.7 & 227.8 & 303.1 & 28.72 & 0.22 \\
& 33 & 230.8 & 227.5 & 296.8 & 40.78 & 0.27 \\
\hline
\end{tabular}

Table 4. Microstructural examination results.

\begin{tabular}{lcccccc}
\hline $\begin{array}{l}\text { Steel } \\
\text { grade }\end{array}$ & Sample & $\begin{array}{c}\text { Grain extension } \\
\text { degree }\end{array}$ & $\begin{array}{c}\text { Grain } \\
\text { degree }\end{array}$ & $\begin{array}{c}\text { Cementite } \\
\text { sort }\end{array}$ & $\begin{array}{c}\text { Cementite } \\
\text { size }\end{array}$ & Impurity \\
\hline & 11 & 2 & $7-6$ & B & 2 & 1 \\
& 12 & 2 & $6-7-5$ & A+B & 1.5 & 1 \\
& 13 & 2 & $7-8$ & B & 2 & 1 \\
& 21 & 2 & $6-7$ & B & 2 & 1 \\
DC03 & 22 & 2 & $5-6-7$ & B & 2 & 1 \\
& 23 & 3 & $8-7$ & B & 1 & 1 \\
& 31 & 2 & 7 & B & 0.5 & 1 \\
& 32 & 2 & $6-5$ & B & 2 & 1 \\
& 33 & 3 & $7-8$ & B & 1 & 1 \\
\hline
\end{tabular}

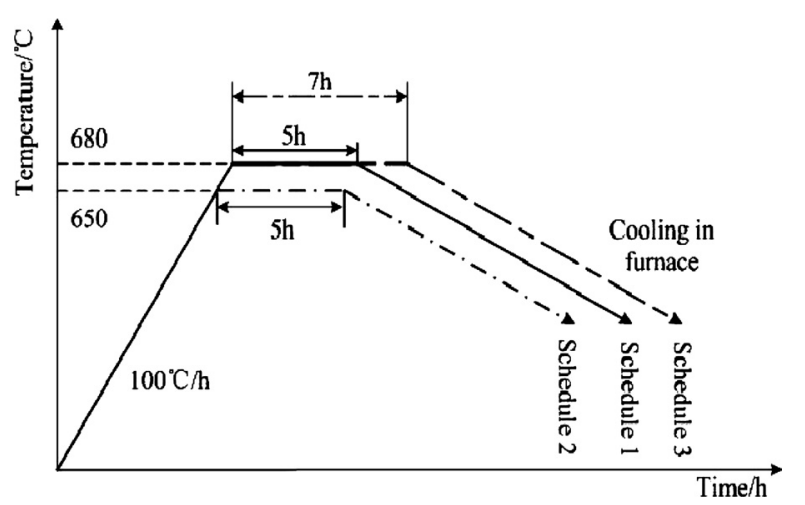

Fig. 1. Annealing schedules used in the simulation tests.

produced with CSP hot-bands (CSS), in which X1 is cold sheets rolled with CSP hot-bands employing higher FDT's followed by lower CT's, while X2 is cold sheets rolled with CSP hot-bands using lower FDT's followed by higher CT's. Sample X3 represents the as-cold-rolled sheets produced with conventional CSP hot-bands (CSC).

\subsection{Annealing Technology in the Tests}

Three kinds of annealing technologies shown in Fig. 1 were applied in annealing simulation tests for as-cold-rolled sheets. Effects of annealing temperature on microstructure and drawing properties of tested steels were considered in annealing technology 1 and technology 2, with annealing technology 1 and technology 3 reflecting the influences of heat treatment time during annealing process.

\section{Results of Microstrucrural Examinations and Drawing Properties Tests}

Annealing simulation tests were carried out on ZJ-7.5-12 vacuum annealing furnace for samples according to the annealing schedules in Fig. 1. A section of each annealed sample was prepared for mechanical property investigation (annealed state) while other sections were used for microstructural examinations. Examinations of mechanical property and drawing property were conducted on Zwick/roll materials testing machine and the results are given in Table 3. Standard metallographic preparation and examination were performed on the annealed specimens with Zeiss optical microscope and results are shown in Table 4.

It is necessary to explain microstructural examination standard for drawing quality sheet steels as follows.

\section{(1) Grain Extension Degree}

There are three grades for grain extension degree, i.e., grade 1 , grade 2 and grade 3, representing equiaxed grain, normal flat-shaped grain and severe flat-shaped grain respectively. Grain extension degree of grade 1 is not acceptable for drawing quality sheet steels. 

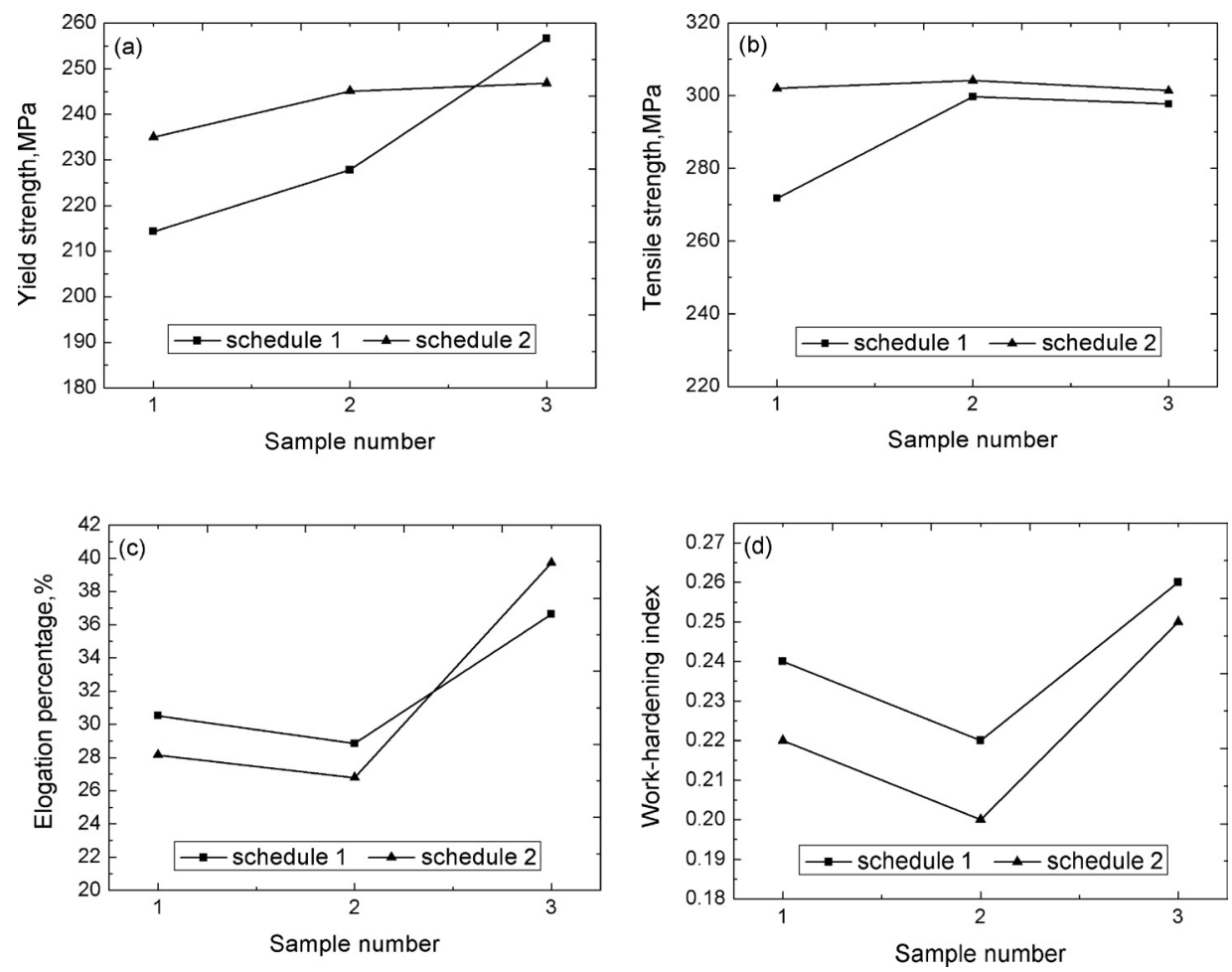

Fig. 2. Comparison of yield strength and tensile strength of annealed samples treated with technology 1 and technology 2. (a) Yield strength; (b) tensile strength; (c) elongation rate; (d) work-hardening index.

\section{(2) Grain Degree}

Grain degree 6, 7, 8 are acceptable for drawing quality sheet steels in the condition of only two different grain degrees existing in microstructure. In other words, five microstructures are eligible for drawing quality sheet steels, i.e., grain $6,7,8,6+7$ and $7+8$.

\section{(3) Cementite}

Cementites are sorted to three grades of $\mathrm{A}, \mathrm{B}, \mathrm{C}$, in which grade $\mathrm{A}$ represents reticular cementite and grade $\mathrm{B}$ and $\mathrm{C}$ are corresponding to dissociative cementite. Dissociative cementite is superior to reticular cementite for drawing quality sheet steels. Moreover, the finer of dissociative cementite particles, the better of drawing properties of formable cold sheets.

\section{Results Analysis of Property Tests}

\subsection{Influence of Annealing Temperature on Sheet Property}

The treating temperature of annealing technology 1 is $680^{\circ} \mathrm{C}$, while the treating temperature of annealing technology 2 is decreased to $650^{\circ} \mathrm{C}$. Influence of annealing temperature on sheets property can be given from these two annealing technologies. Figure 2 shows the mechanical properties and formability properties of annealed specimens X1, $\mathrm{X} 2$ and X3 treated with annealing technology 1 and technology 2 .

It can be seen from Fig. 2 that both yield strength and tensile strength increase with the decrease of annealing temperature, and elongation rate and work-hardening index decrease with the decrease of annealing temperature, which is coincidental to results in literature. ${ }^{9,10)}$

Deterioration of drawing property with the decrease of annealing temperature perhsps results from the incomplete recrystallization of samples. It takes longer time to complete recrystallization under lower annealing temperature. Therefore, it is harmful for drawing property of cold sheets to decrease annealing temperature. The annealing temperature for experimental DC03 formable sheets should be higher than $680^{\circ} \mathrm{C}$ in order to obtain good drawing property.

\subsection{Effect of Keeping Time of Temperature on Sheet Property}

The keeping time of temperature of annealing technology 1 and technology 3 is respectively five hours and seven hours on the purpose of observing the effect of keeping time of temperature on microstructures and properties of annealed samples. Figure 3 compares the yield strength, tensile strength, elongation rate and work-hardening index of sample X1, X2 and X3 annealing treated with technology 1 and technology 3 .

It is noted that increase of keeping time of temperature doesn't significantly affect the properties of annealed samples. The drawing property of annealed sheets has not been obviously improved although keeping time of temperature for technology 3 increases to $7 \mathrm{~h}$. This is because recrystallization for as-cold-rolled samples has been finished under annealing technology 1 and elongation of treatment time has little effect on drawing property of cold sheets, which means that drawing property of cold sheets cannot be improved by elongation of heat treatment time if complete recrystallization can be finished during heat treatment.

\subsection{Properties of Annealed Cold Sheet Samples Rolled with Different CSP Hot Bands}

Cold-rolled sheets produced by two kinds of CSP hotbands, taken from Cold Plant, Lianyuan Steels, were used 

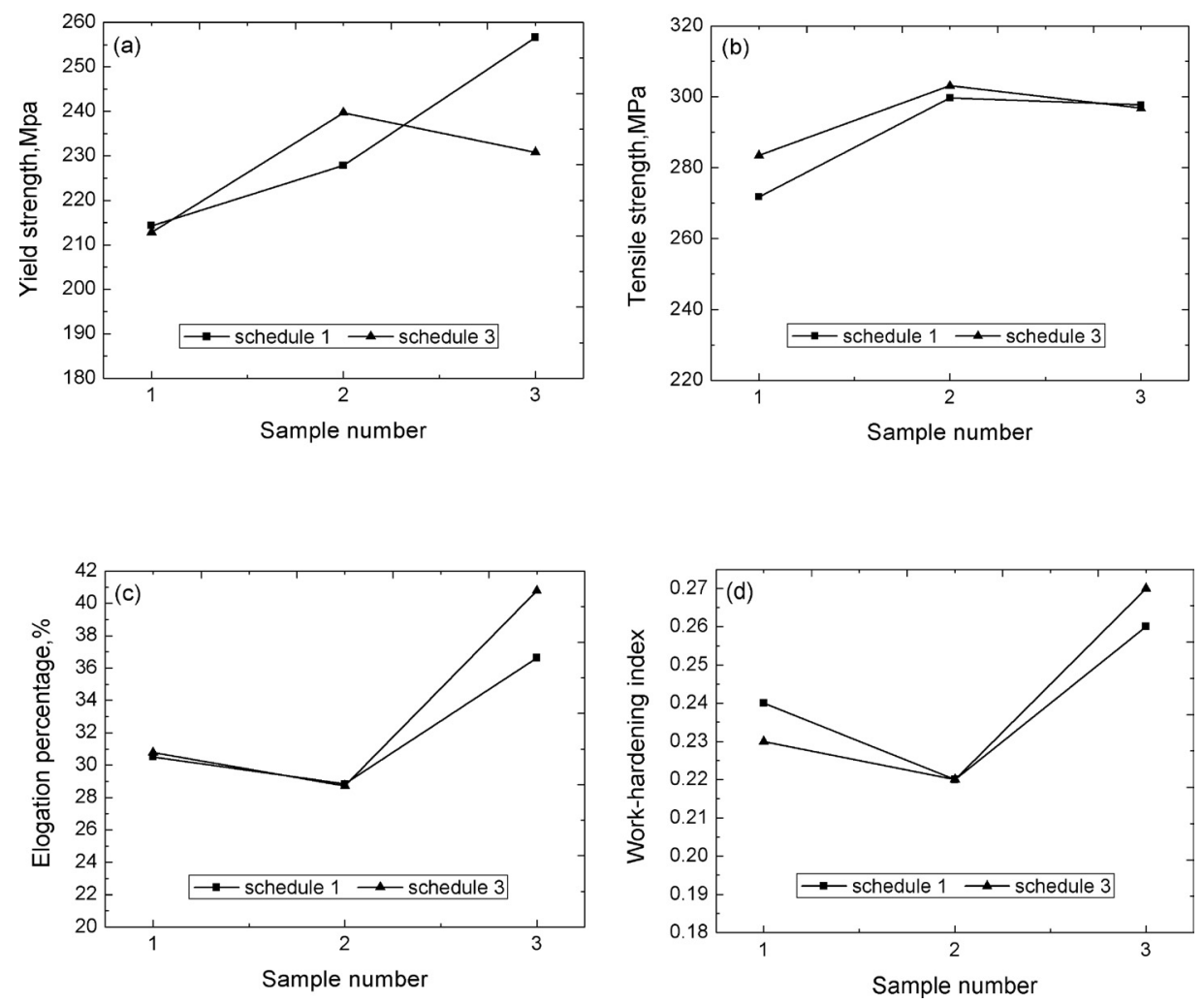

Fig. 3. Comparison of yield strength and tensile strength of annealed samples treated with technology 1 and technology 3. (a) Yield strength; (b) tensile strength; (c) elongation rate; (d) work-hardening index.

Table 5. Properties of two kinds of annealed samples.

\begin{tabular}{ccccc}
\hline Sample & $\mathrm{Rp}_{0.2}, \mathrm{MPa}$ & $\mathrm{R}_{\mathrm{m}}, \mathrm{MPa}$ & $\mathrm{A}_{80}$ & $\mathrm{n}$ \\
\hline 11 & 214.3 & 271.8 & 30.52 & 0.24 \\
12 & 227.8 & 299.7 & 28.84 & 0.22 \\
21 & 235.0 & 302.0 & 28.15 & 0.22 \\
22 & 245.1 & 304.2 & 26.79 & 0.20 \\
\hline
\end{tabular}

in the annealing experiments, one of which is $\mathrm{X} 1$, rolled with hot strips of higher FDT $\left(927^{\circ} \mathrm{C}\right)$ followed by lower $\mathrm{CT}\left(568^{\circ} \mathrm{C}\right)$, and $\mathrm{X} 2$ was rolled with hot-bands using lower FDT $\left(890^{\circ} \mathrm{C}\right)$ followed by higher $\mathrm{CT}\left(646^{\circ} \mathrm{C}\right)$. The properties of two kinds of annealed samples are given in Table $\mathbf{5}$.

It is clear that properties differences exist between samples produced by hot-bands with different FDT's and CT's. Compared to specimen $\mathrm{X} 2$, sample $\mathrm{X} 1$ has lower yield strength and tensile strength, higher elongation rate and work-hardening index. This implies that CSP hot rolling schedule significantly affects the drawing properties of following cold sheets, which is accordant to the results of literature. ${ }^{11)}$ The drawing properties of cold sheets can be improved by using CSP hot-bands rolled with higher FDT and lower CT. This is due to the fact that more solute particles dissolved in CSP hot bands rolled by higher FDT and lower $\mathrm{CT}$ and these particles separate out during annealing process to help formation of flat-shaped grain, which is desired microstructure for drawing quality steel sheets. Figure 4(a) is TEM micrograph of sample rolled at higher FDT and lower CT after $2 \mathrm{~h}$ heat treatment, while Fig. 4(b) is TEM micrograph for sample rolled at lower FDT and higher CT with same heat treatment. It is clear that more fine precipitates separated out in the sample rolled at higher FDT and lower CT.
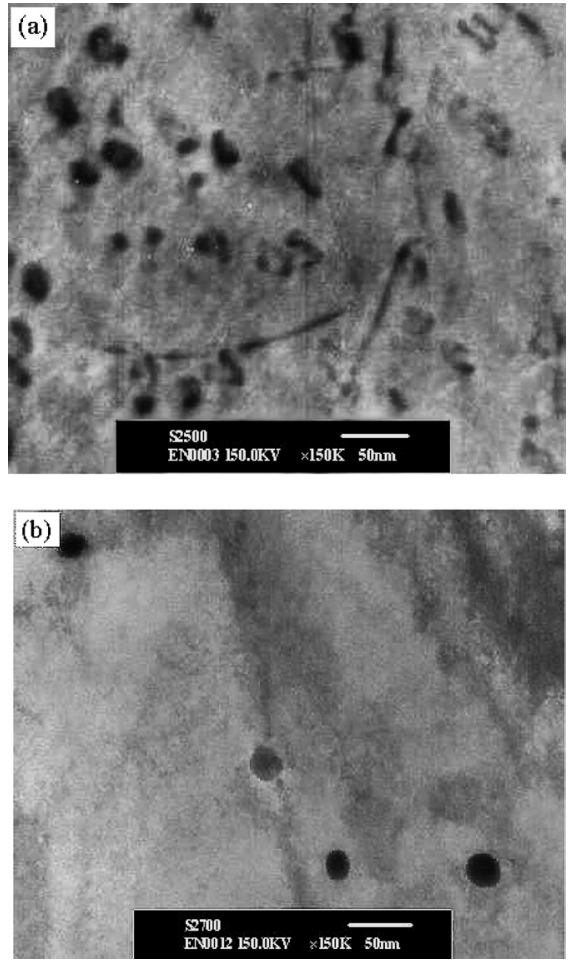

Fig. 4. TEM photos of different samples after $2 \mathrm{~h}$ heat treatment. (a) Sample at higher FDT and lower CT; (b) sample at lower FDT and higher CT.

\subsection{Properties of Annealed CSS and CSC Samples}

Two kinds of cold sheets, CSS and CSC, were used in the simulation annealing tests in order to observe the effect of different hot bands on property of annealed cold sheets. Sample X1 is cold-rolled sheets by CSP hot bands, taken 
Table 6. Properties of annealed CSS and CSC samples.

\begin{tabular}{ccccc}
\hline sample & $\mathrm{Rp}_{0.2}, \mathrm{MPa}$ & $\mathrm{R}_{\mathrm{m}}, \mathrm{MPa}$ & $\mathrm{A}_{80}$ & $\mathrm{n}$ \\
\hline 11 & 214.3 & 271.8 & 30.52 & 0.24 \\
13 & 256.6 & 297.7 & 36.63 & 0.26 \\
21 & 235.0 & 302.0 & 28.15 & 0.22 \\
23 & 246.8 & 301.4 & 39.72 & 0.25 \\
\hline
\end{tabular}

from Lianyuan Steels, while sample X3 is cold-rolled sheets by conventional hot bands, taken from WISCO. Property values of annealed samples are presented in Table 6.

As can be seen in Table 6, for two annealing technologies, drawing properties of CSC are superior to those of CSS, which means that different annealing technology should be applied when drawing quality cold sheets are produced by CSP hot bands.

\section{Analysis of Microstructure Examination}

\subsection{Microstructure of Annealed Samples Rolled with Different CSP Hot Bands}

It can be seen from Table 3 that for all three annealing technologies, microstructures of sample X1 rolled with CSP hot bands of higher FDT and lower CT are superior to those of sample X2 rolled with CSP hot bands of lower FDT and higher CT. Moreover, three different grain grades exist in microstructure of sample X2, which are not acceptable for drawing quality sheets, although there is no much difference in grain extension degree, cementite particles and impurity for annealed samples of CSS and CSC. The microstructure examination results are corresponding to the property examination results discussed above in Sec. 4.

\subsection{Microstructure of Annealed CSS and CSC Sam- ples}

It can also be found in Table 3 that after treated with same annealing technology, microstructure of CSC sample $\mathrm{X} 3$ is better than that of CSS sample X1 and X2 for drawing quality sheets. Finer grains exist in microstructure of sample X3 compared to sample X1 and X2, with much smaller cementite particles distributing in sample $\mathrm{X} 3$, which is useful to improve the drawing property of cold sheets. Microstructure of samples is consistent with property examination discussed in Sec. 4.

\section{Conclusions}

Different annealing technologies were performed on CSS and CSC samples and the mechanical properties and microstructures of CSS and CSC samples were investigated after annealing treatment. The results are compared between different tested samples. From these investigations, the following conclusions can be drawn:

(1) Annealing temperature should be higher than $680^{\circ} \mathrm{C}$ when DC03 drawble cold sheets are produced with CSP hot bands.

(2) Compared to CSP hot bands of lower FDT and higher CT, CSP hot strips of higher FDT and lower CT are more suitable to be used to produce drawing quality sheets.

(3) Microstructures of annealed sheets rolled with CSP hot strips of higher FDT and lower CT are superior to those of annealed sheets rolled with CSP hot strips of lower FDT and higher $\mathrm{CT}$.

(4) Under the same cold rolling schedule and annealing technology, microstructures and drawing properties of CSC sheets are superior to those of CSS sheets.

\section{Acknowledgment}

The authors wish to thank Liuanyuan Iron and Steel (Group) Company for financial support to this study. This research project is also financially supported by the key research item of Hubei Education Bureau (Project No.: 2002A01013).

\section{REFERENCES}

1) W. Y. Choo and C. M. Bae: ISIJ Int., 42 (2002), S47.

2) P. Ghosh, B. Bhattacharya and R. K. Ray: Scr. Mater, 56 (2007), 657.

3) J. X. Li, Z. Y. Liu, C. R. Gao, Z. D. Wang, X. H. Liu and G. Wang: J. Mater. Process. Technol., 67 (2005), 132.

4) A. Guillet, E. Es-Sadiqi, G. L'esperance and F. G. Hamel: ISIJ Int., 36 (1996), 1190.

5) M. R. Barnett and J. J. Jonas: ISIJ Int., 37 (1997), 706.

6) M. Militzer: ISIJ Int., 47 (2007), 1.

7) M. Ferry, D. Muljono and D. P. Dunne: ISIJ Int., 41 (2001), 1053.

8) J. Pero-Sanz, M. Ruiz-Delgado, V. Martinez and J. I. Verdeja: Mater. Charact., 43 (1999), 303.

9) H. F. G. de Abreu, A. D. S. Bruno, S. S. M Tavares, R. P. Santos and S. S. Carvalho: Mater. Charact., 57 (2006), 342.

10) A. K. Srivastava, G. Jha, N. Gope and S. B. Singh: Mater. Charact., 57 (2006), 127.

11) M. Ferry, D. Yu and T. Chandra: ISIJ Int., 41 (2001), 876. 